\title{
REGIONAL INTEGRATION AND INDUSTRIAL DEVELOPMENT: THE AFRICAN EXPERIENCE
}

\author{
Ugochukwu Sebastine Ugwuegbe \\ African Heritage Institution, Enugu. \\ Chibueze Ekene Onyeke \\ University of Nigeria, Enugu Campus \\ Chinwe Celestine Eke \\ University of Nigeria, Enugu Campus
}

\begin{abstract}
:
This study examined the role of Africa's regional integration in promoting industrialization in the continent. We traced the effort of various Regional Governments, Regional Economic Communities (RECs) and the African Union (AU) in promoting industrialization in Africa. Industrial development in Africa is still at the primordial level, making Africa depend mainly on primary commodities for export and leading to the reduction in the continent's share of the global export of manufactured goods, increase in unemployment, and poverty. The study, proffers the argument that regional integration is a veritable instrument for achieving structural transformation and industrial development in Africa. We therefore recommended that the Regional Economic Communities should be reorganized in order to facilitate the ratification and implementation of the regional integration agenda which has direct consequence on sustainable industrialization in Africa.
\end{abstract}

\subsection{Introduction:}

Industrialization in Africa has remained elusive, giving rise to the region's dwindling share of global export of manufactured goods, increased dependence on the primary commodities for export, reduction in the global value chain and a declining share of the global manufacturing value added. According to UNIDO (2016), Africa contributed only $1.6 \%$ of the global manufacturing value added in 2014 while exports of Less Developed Countries (LDCs) in Africa amounted to only $1 \%$ of the total global export in 2013. Primary commodity exports among LDCs in Africa represented a total of $67 \%$ of the regions' total export in 2014, with almost half of it from fuel. The region has also witnessed a shallow participation in the global value chain, accounting for only $2.2 \%$ of the global value chain in 2011. These account for the increasing poverty level in Africa, high unemployment rate, and low standards of living, among other social ills. The reason for the widening gap in industrialization in Africa has been attributed to lack of competitiveness, weak logistics and trade facilitation systems, the absence of accreditation frameworks and slow regional integration in Africa (UNIDO 2016).

A concerted effort towards promoting industrial development in Africa through enhanced regional integration has given rise to various regional bodies, among which are the Economic Community of West African States (ECOWAS), West African Monitory Zone (WAMZ), West African Economic and Monetary Union (WAEM), East African Community (EAC) and the Southern African Development Community (SADC). These regional blocks have contributed in various shapes and forms to improving global competitiveness as well as Africa's improved trade policies which have accelerated intra-African and inter-regional free movement of goods and people. It is against this background that this paper, however, seeks to investigate the role of regional integration in industrial development in Africa. 


\subsection{An Overview of Africa's Regional Integration Strides:}

Regional integration has been identified as a fundamental factor necessary to increasing the global competitiveness, industrialization, and standards of living of the African continent, (UNIDO 2016). This realization gave rise to the establishment of the defunct Organization of African Unity in 1963, which was replaced by the African Union (AU) in 2002. The commitment by various African Heads of State and Government to advance the agenda for increased economic, social and cultural cooperation and integration among African countries in June 1991, resulted in the endorsement of the Treaty of African Economic Community (AEC). The AEC Treaty was established for the purpose of promoting economic, social and cultural development as well as fostering African economic integration with a view to promoting self-sufficiency and endogenous development, and designing a framework for industrial development, human and material resource mobilization for the continent's overall global competitiveness.

The AEC Treaty, which is popularly known as the Abuja Treaty (because the $27^{\text {th }}$ ordinary session of the Assembly where the Treaty was signed was held in Abuja), provided for the establishment of Regional Economic Communities (RECs) in Africa. The Treaty subdivided the African continent into 5 sub-regional groups comprising West Africa, Southern Africa, North Africa, East Africa and Central Africa each with its own regional economic organization which serves as a building block for the overall integration of the African economies. However, the AU, on inception in 2002, recognized eight major regional economic organizations which operate in each of the five major sub-regions with some having overlapping functions as well as countries having dual membership in one or two of the regional organizations. The appendix showcases the membership of various regional organizations according to the major regional economic blocks.

The RECs, among other things, focus on regional infrastructural integration, productive integration, financial and macroeconomic integration, free movement of people and trade integration through which they have contributed in one way or the other to the industrial growth and development of the continent. Different policies along these integration targets have been formulated with a gradual implementation which has enhanced free movement of people and goods from one region to another with little or no restriction. Despite the achievements of these RECs in promoting development in the continent, the current structure which allows one country to be a member of more than one regional economic organization, as well as the emergence of multiple regional economic organizations with overlapping roles, inhibits the effectiveness of the RECs. Out of eight (8) RECs reorganized by the AU, nine countries (Tanzania, Sudan, Rwanda, Libya, Kenya, Eritrea, Djibouti, Congo and Burundi) are members of three different regional integration groups. Similarly, eleven countries, out of 54 member nations of the AU, belong to only one regional economic organization; the rest are members of two or three RECs.

In West Africa, for instance, ECOWAS, UEMOA and MRU formulate and implement different trade and financial policies to be ratified and implemented by member nations, coupled with a heavy financial burden for members to meet. These, however, led to the recommendation by the Economic Commission for Africa that regional economic communities should be reorganized to align with the five sub-regional economic blocks identified in the Abuja Treaty. They recommended that each economic block should have one regional economic community (i.e North Africa Economic Community (NAEC) for North African countries, Southern Africa Development and Economic Community (SADEC) for Southern African countries, Central 
African Economic Community (CAEC) for Central African countries, East African Economic Community (EAEC) for East Africa countries, West African Economic Community (WAEC) for West African countries).

\subsection{Regional Integration Policies that Impact on Industrial Development in Africa:}

The continent has adopted and implemented varied policies and programmes aimed at accelerating industrial growth and development among all the countries in Africa, thereby striving to promote the continent's global competitiveness. These policies are structured in line with the five key regional integration agenda. Each of the five dimensions of the regional integration agenda has specific indicators measuring progress on each of the integration agenda. Figure 1 presents the five dimensions of the agenda and the sixteen associated indicators.

Policies formulated and implemented in line with these integration agenda that have contributed positively or negatively to the industrial growth and development of the continent include, but not limited to the following:

\section{Productive Integration:}

One of the key policies formulated and implemented which may impact positively or negatively on industrial growth and development among countries in Africa is the industrial tariffs Structure. The tariff structure for the importation of capital and intermediate goods is designed with the aim of supporting industrialization in the continent. Unfortunately, the rate of import-weighted tariffs on intermediate goods imported into Africa is significantly higher than those of the Eastern and South-East Asia experiencing a significant increase in industrialization and the rest of the world. The only exception to this is food and beverage tariffs.

The difference in the industrial import tariffs is particularly large for processed industrial supplies, parts and accessories of capital goods and parts and accessories of transport equipment all of which form import inputs for manufacturing industries (ECA, 2016). This high industrial tariff, however, raises the cost of industrialization on the continent of Africa as against the rest of the other regions in the world. On the other hand, the import-weighted tariffs are administered in two different strata, one for intra-African imports and the other for inter-African imports. The intra-African import-weighted tariffs for capital and intermediate goods are 4.2 and $2.1 \%$ respectively as against that of inter-African import-weighted tariff for capital and intermediate goods which are $4.9 \%$ and $5.8 \%$ respectively (ECA, 2016). This shows a significant difference between import tariffs on intermediate goods imported from outside African countries and those imported within Africa. The marginal difference between the rate of capital goods in intra-African and inter-African imports is to encourage industrial production by reducing the cost of machinery and other capital inputs for production which are still sourced heavily from outside the continent. This approach, however, gives African countries the opportunity to promote their internal technological development.

Unfortunately, due to the low level of technological development in Africa which is currently not sufficient to provide for the needed intermediate goods necessary for industrial production, there may be a limit to the uses of these intermediate goods for production processes thereby reducing the possibilities for the export of transformed products in the short run, but if African firms take advantage of this import protection, in the long run, their global competitiveness will improve significantly beyond what it is now. The adoption of the Continental Free Trade Agreement (CFTA) would also lower the intra-African tariff barriers further and as well help 
to boost intra-African trade in intermediate goods and the development of African industrial supply chains to enhance the global competitiveness of the continent.

\section{Figure 1: The Five Dimensions of the Regional Integration Agenda with their Specific Indicators}

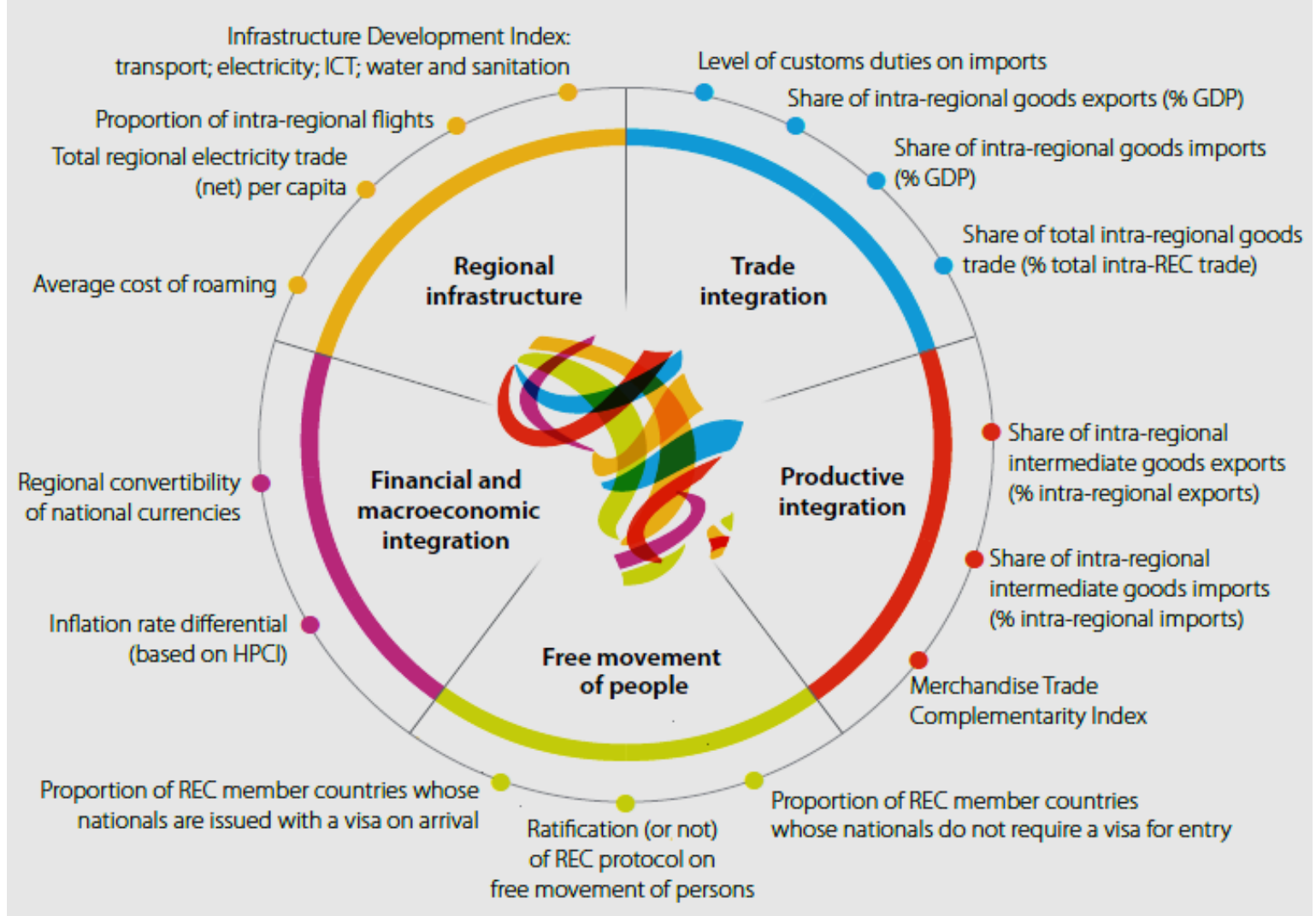

Source: Africa Regional Integration Index Report 2016

\section{Trade Integration:}

The indicators of trade integration are based on four key measures which are: the share of intra-regional goods exported as a percentage of GDP, share of intra-regional import of goods as a percentage of GDP, share of total intra-regional goods traded as a percentage of GDP, and level of customs duties on imports; each of these is designed to promote trade and industrialization in Africa. Most of the regional economic communities adopted the Free Trade Agreements (FTA) which every member of the regional economic block is expected to ratify and implement. However, there exists at the continental level, the Continental Free Trade Agreement (CFTA) which strives to reduce the internal tariffs on both the intermediate and consumer goods imported from countries within the continent. The import-weighted tariffs imposed on consumption goods for intra-African import is lower than that of inter-African. The high rate of tariffs on consumption goods imported outside Africa continent as against those produced internally is to encourage domestic value addition and processing in the African continent. The report of the ECA 2016 indicates that import-weighted tariffs for consumption and other goods are 7 and 5.8\% respectively for intra-African imports, while the tariff rates for consumption and other goods imported from outside the continent stood at 14.7 and $17.4 \%$ respectively. The high rate of import tariffs for consumption and other goods imported from outside the continent is to promote industrial development within the continent of Africa. 


\section{Regional Infrastructure:}

One of the key setbacks to industrial development in Africa is the poor state of infrastructure in the region. The Regional Integration agenda specified four key indicators to measure the level of infrastructural development in the continent which is based on the following indices; infrastructural development in transportation, electricity, Information and Communication Technology (ICT), the average cost of roaming as well as developments in water and sanitation. The physical integration of the transport system adopted by all regional economic communities in Africa has improved all forms of the transport system in Africa providing a conducive environment for industrial development in Africa.

The convention on inter-state roads has provided a platform for RECs to focus effectively on the integration of roads, railways, maritime transport, inland waterways, and civil aviation. These will create physical access to all the regions of the continent making it possible for both raw materials and finished goods to easily move from one country to another within the region, hence promoting industrial development. The effort in regional integration in communication as indicated in the agreements of the RECs, focuses on policy convergence, integration of physical facilities, connectivity as well as the promotion of exchange programs, more especially on broadcasting.

The main aim of policy convergence in communication is to promote trade and finance and reduce the cost of production and services by making communication and information linkages accessible and affordable among the Africa Region and the rest of the world. Meanwhile, reductions in the cost of communication should result in lower production costs, and since investors are rational and will move their investments to areas with lower cost and higher returns, this will lead to industrial development in the continent. Electricity is also one of the key drivers of industrialization and various efforts have been put in place to improve the amount of energy produced and as well enhance distribution of generated energy among countries in the RECs.

\subsection{The Need for Industrialization in Africa:}

There are several reasons why African countries and other less developed and developing nations of the world must embrace industrialization if they must improve the living standards of their citizens. The following reasons account for the need for industrialization in Africa:

1. Meeting the Sustainable Development Goals (SDG): goal nine (9) of the SDGs is designed with particular focus on building resilient infrastructures, promoting inclusive and sustainable industrialization and fostering innovation. Meanwhile, it is important to note that without industrialization African countries are unlikely to achieve the 2030 global goals. Deliberate effort is required in promoting industrialization among Africa countries in order to drive the continent to the targeted level of development.

2. Increased Job Creation: there is a positive relationship between inclusive and sustainable industrial development and job creation, food security, innovation, skill development and equitable growth most of which are parameters needed for the elimination of poverty in Africa. The increasing rate of unemployment in Africa associated with rapid growth in population is a key factor necessitating industrialization in Africa. The World Bank report on global unemployment for 2017 indicates that the Middle East and North Africa have the highest unemployment rate of $28.6 \%$ compared to other regions of the world like the European Union with $19.2 \%$. The unemployment rate for Sub-Saharan Africa stood at 14.2\% higher than the world unemployment rate 
of 13.6. This, no doubt, points to the need for increased job creation in the continent of Africa through effective and sustainable industrial development.

3. Structural Transformation: hardly has any country in the world progressed from poor to rich nation without effective and sustained structural transformation from the agrarian or resource-based economy, towards industrialization and then to a servicebased economy. This transformation is necessary to provide for wealth creation by promoting economic integration and increased productivity. Africa, currently, is still at the resource-based stage of structural transformation, slowly encroaching into the industrialization threshold, making agriculture the largest employer of labour in the continent. This, no doubt, is responsible for the continent's poor value chain and decreasing global competitiveness, hence the need for sustainable industrial development for Africa.

4. Dwindling fiscal revenues: the level of tax revenues in Africa has remained significantly low compared to other regions in the world. In 2015, a report by UNIDO showed that the total tax revenue as a percentage of GDP for Africa (from a sample of 16 countries) stood at $19.1 \%$ as against $34.3 \%$ in the OECD countries and $22.1 \%$ in Latin America and the Caribbean region. Similarly, the tax on incomes and profits as a percentage of GDP for Africa in 2015 was $6.2 \%$ and $11.6 \%$ for OECD countries, underscoring the need for effective and sustainable industrialization in order to increase the continent's tax revenue to enable the government to provide the social amenities needed for the development of the continent.

\subsection{Factors Responsible for the Slow Pace of Industrialization in Africa:}

Several reasons account for the increasing industrialization gap between Africa and other regions of the world. This gap in the level of industrialization between Africa and the rest of the world is evidenced in the low level of trade in merchandise which represents only $11 \%$ of the total trade in the continent within a period of 5 years, as against $50 \%$ in Asia and $70 \%$ in Europe (UNIDO 2016). This, however, has made it difficult for firms in the continent to effectively take advantage of the huge market potential associated with increasing population in Africa. The following are key challenges faced in attempt to promote industrialization in African though not exhaustive.

\section{Sluggish Regional Integration in African:}

Africa in relation to other continents of the world has remained the least regionally integrated continent. This is evidenced in the trade barriers among countries in Africa which are most often higher than those between them and the rest of other regions of the world. There has been a significant increase in the volume of trade between the African continent and the rest of the world, resulting in a double-digit growth in inter-African trade. For over a decade now, trade in Africa has been dominated by inter-African trade especially with the developed countries, with a heavy concentration in natural resources and primary commodities. Although trade in Africa is dominated by inter-African trade, intra-African trade eventually, is more diversified than that of the rest of the world, with manufacturing accounting for two-thirds of the intra-African trade. The share of intra-African trade in 2013 accounted for $16.3 \%$ of the continent's total trade which is the lowest compared to other regions in the globe. The level of value addition in intra-African trade has remained significantly low, representing only $9.5 \%$ of the total value of trade in 2011, meaning that most of the values added are imported from other 
regions outside the continent of Africa, which is a clear indication of the continent's low level of global competitiveness.

The increasing fragmentation of the African market due to poor integration is very costly for all African countries, leading to loss of wealth creation as well as it's equitable distribution; and no prospects to realize the economies of scale and scope. The poor provision of regional public goods especially infrastructural facilities, has hindered rapid growth in regional integration leading to the slow pace of sustainable industrialization in Africa.

\section{Weak global competitiveness:}

Over 34 countries in Africa are classified as less developed countries due to various factors which have contributed significantly to the continent's lack of global competitiveness. Meanwhile, the weak global competitiveness can be attributed to poor business environment, low institutional capacity, the dearth of adequate infrastructural facilities like roads, rail, and flight transportation systems, energy, and information and communication technology. These factors increase the cost of doing business in Africa and, as well, increase the cost of production, hence weakening the industrial development strides in Africa.

\section{An Increasing Preference for foreign manufactured goods:}

The share of the continent's import of manufactured goods has increased significantly in relation to the world total, resulting in over $3.2 \%$ over a period of 10 years (2005-2014), making the continent one of the fastest-growing importers of manufactured goods across the globe. The increasing preference for foreign goods has not only hindered the industries' development in the continent but as well exacerbated the poverty level in Africa as most industries are forced into extinction with the associated loss of jobs and incomes.

\section{Deficit Infrastructural Facilities:}

One of the significant drawbacks for industrialization in Africa is the paucity of infrastructural facilities. Africa faces a humongous infrastructural deficit which accounts for 30 to 60 percent of firms' productivity losses; 40 to 80 percent of this loss is attributable to the energy sector (ADB 2017). Paucity of quality energy places additional costs on firms such as idleness of workers, spoilt materials, lost production, damaged equipment and restart cost, etc. Meanwhile, it was estimated that between the period 2010 and 2016, an average of 8.5 power outage would be recorded per month within an interval of 4.1 hours on the average. The estimated costs associated with power outage stood at $5.4 \%$ of firms' annual sales; and to mitigate this cost, $51.3 \%$ of firms employ their own generator as an alternative source of energy which only covers about $13.4 \%$ of their energy consumption. The regional road networks to connect the entire continent in order to take advantage of the huge market potential of Africa is in very deplorable state. Same is the case with the rail and inland waterways, not to mention the aviation sector which is also at the formation stage, all these and more contribute significantly to sluggish industrial development in Africa.

\section{Unfavourable financial facilities for industrial development:}

The inability of firms to access affordable credit facilities is one of the most binding constraints on Africa's industrial development. This, however, is attributed to information asymmetries for project profitability as well as the dearth of collaterals or an effective credit track record, and more importantly, the underdeveloped nature of the African financial markets. The credit gap that exists among the formal sectors, micro, small and medium-sized enterprises has been estimated to be over US\$ 136 billion (ADB 2017). Despite these other constraining factors, 
long-term and equity financing is especially rare in Africa, while almost 60 per cent of credits in Africa are short term and less than 2 per cent of the loans are for a period of ten years and above. These have militated against sustainable industrial development in Africa.

\subsection{Conclusion and Policy Recommendations:}

Regional integration, no doubt, has an inherent potential to fast-track the industrial development of the African continent if every country will effectively play their role at the regional economic community level by implementing and ratifying all the policies, treaties and protocols initiated at both regional and continental level. Regional integration has the capacity to create an industrial hub in Africa through increased market share and economies of scale; promotion of investment and productive integration; infrastructural integration and financial system integration. Various efforts have been made to advance the level of regional integration in Africa to conform with the other parts of the world like the European Union, with the aim of promoting sustainable industrial development, yet industrialization in Africa still remains at the primary stage. This, no doubt, is responsible for the continent's dwindling share of the global exports. The poor state of industrialization in Africa has also resulted in over $40 \%$ of the continent's imports comprising consumables only. Sequel to the above conditions, the study makes the following recommendations:

1. Introduction of effective and legitimate standards for Africa: the Regional Economic Communities should ensure that sound and legitimate standards are strictly followed by all regions in their production processes especially as it concerns the role of origin, if the target of industrialization must be achieved. One of the key strategies to improve industrialization in Africa is compliance with sound and legitimate standards which can be achieved through an enhanced trade capacity and competitiveness, facilitation of mutual benefits in industrial products, integration of firms into the regional and global value chains as well as improved efficiency of production and trade.

2. Reductions in the industrial tariff structure: the current level of industrial tariffs should be reviewed downwards to make the African continent more viable and globally competitive. The current level of import-weighted tariffs on Africa's intermediate imports is significantly greater than that of the Eastern and South East Asian countries which are regions with high levels of industrialization and the rest of the world as well. The differences are largely seen in most of the industrial supplies, parts and accessories of capital goods, and parts and accessories of transport equipment, which are all parts of the inputs for the manufacturing industries.

3. Ratification of the Continental Free Trade Area (CFTA) protocols by all the countries in Africa: due to the inherent potentials for trade-driven industrialization which the CFTA promises to offer, all the countries in Africa should effectively ratify and sign the trade agreement if the goal of full industrialization by 2063 will be achieved.

4. The implementation of various advocacy programmes to re-orientate African consumers on the need for increased preference for goods made in Africa. This will help to revert the current trend of over $40 \%$ import of consumable goods into Africa even with a significant increase in the tariffs on imported goods outside the continent as against goods produced in Africa.

5. Bridging the credit gap that exists among formal sectors, small and medium-sized enterprises: the regional economic communities, in collaboration with all the existing regional financial institutions in various regions, should seek to prioritize credit facilities to the advantage of micro, small and medium-sized enterprises which have the potentials for smooth structural transformation. 
6. Improved Infrastructural Facilities: all Heads of State and Government of various countries in Africa should collaborate effectively with the regional economic communities as well as regional development financial institutions in providing funds for the proposed intra-African highways for effective movement of goods and people and energy (electricity) to reduce the costs of production incurred by firms etc.

7. Restructuring of the current regional economic communities: the current regional economic communities should be reorganized to conform to the provisions of the Abuja Treaty (subdividing the African continent into five basic groupings) so as to avoid multiple memberships of RECs. By this, we, therefore, suggest that a total of five regional economic communities should exist in line with the five regions created by the Treaty so as to enhance effective participation of member countries.

\section{References}

ECA. (2016). African Regional Integration Index Report 2016.

ECA. (2017). Transforming Africa through Smart Trade and Industrialization. Designed and printed by the ECA Printing and Publishing Unit.

ECA. (2006). Assessing Regional Integration in Africa II, Rationalizing Regional Economic Communities.

UNIDO. (2016). Industrialization in Africa and Least Developed Countries Boosting growth, creating jobs, promoting inclusiveness and sustainability: A Report to the G20 Development Working Group by UNIDO.

https://www.afdb.org/en/news-and-events/why-does-africas-industrialization-matterchallenges-and-opportunities-17569/

\section{Appendix}

Five Major Regions in Africa and their Regional Economic Communities

\begin{tabular}{|l|l|l|l|l|}
\hline West Africa & Southern Africa & North Africa & East Africa & Central Africa \\
\hline $\begin{array}{l}\text { Economic } \\
\text { Community } \\
\text { of West } \\
\text { African }\end{array}$ & $\begin{array}{l}\text { Common } \\
\text { Market for } \\
\text { States } \\
\text { (ECOWtern and } \\
\text { Southern Africa } \\
\text { (COMESA) }\end{array}$ & $\begin{array}{l}\text { Antergovernmental } \\
\text { Authority on } \\
\text { Development } \\
\text { (IGAD) }\end{array}$ & $\begin{array}{l}\text { East African } \\
\text { Community } \\
\text { (EAC) }\end{array}$ & $\begin{array}{l}\text { Economic } \\
\text { Community of } \\
\text { Central } \\
\text { African States } \\
\text { (ECCAS) }\end{array}$ \\
$\begin{array}{l}\text { Community Sahel- } \\
\text { Saharan } \\
\text { States (CEN- } \\
\text { SAD) }\end{array}$ & $\begin{array}{l}\text { Southern } \\
\text { African } \\
\text { Development } \\
\text { Community } \\
\text { (SADC) }\end{array}$ & & & \\
\hline $\begin{array}{l}\text { Arab } \\
\text { Maghreb }\end{array}$ & & & & \\
\hline
\end{tabular}




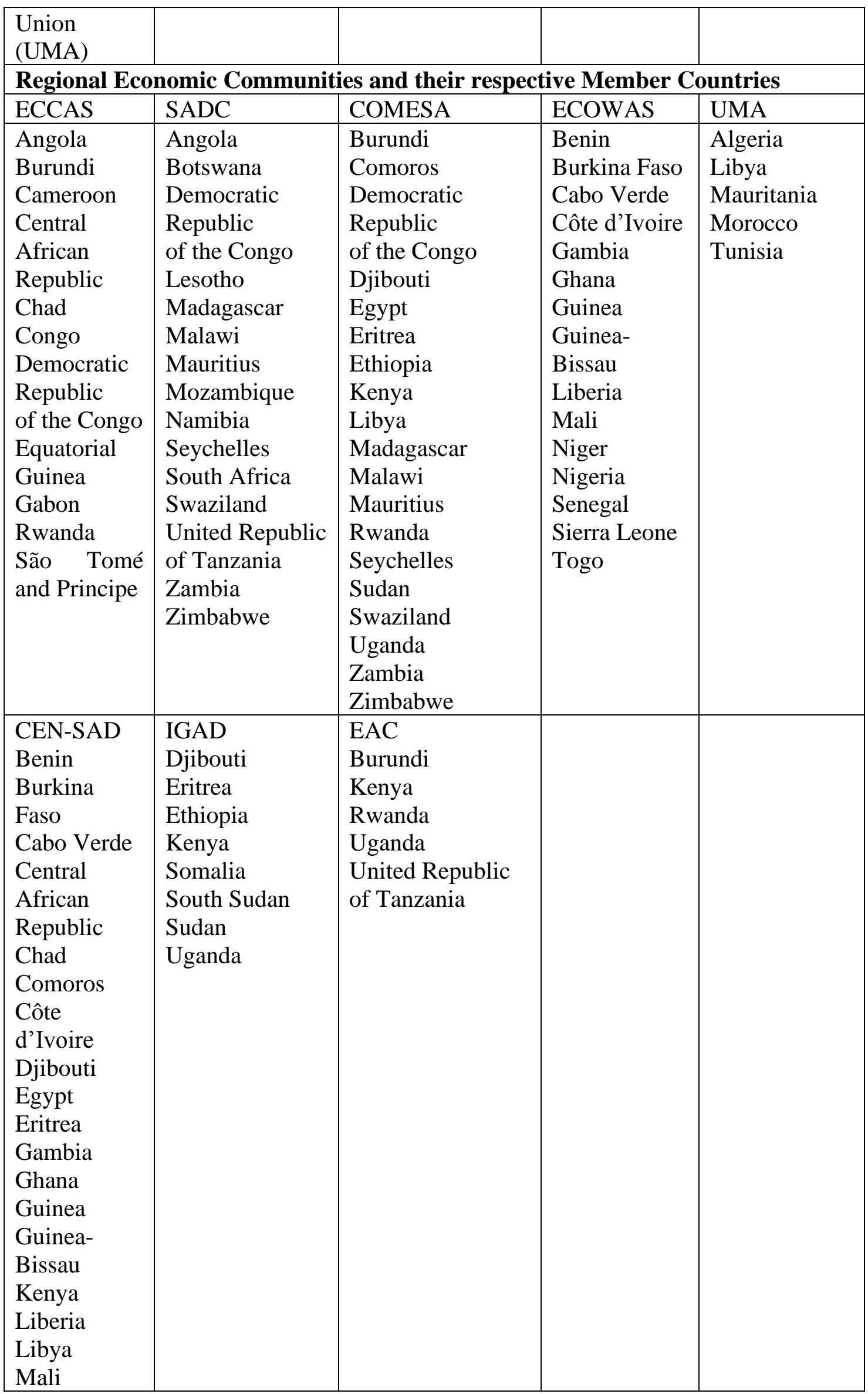




\section{Mauritania}

Morocco

Niger

Nigeria

São Tomé

and Principe

Senegal

Sierra Leone

Somalia

Sudan

Togo

Tunisia 